\title{
RESPONSABILIDADE DEMOCRÁTICA COMO PRESSUPOSTO DE UMA TEORIA DA INTERPRETAÇÃO: DISCUSSÃO EM TORNO DA ADI 4983/CE
}

\author{
ANDREAS JOACHIM KRELL ${ }^{1}$ \\ Pedro de Oliveira Alves ${ }^{2}$
}

RESUMO: Partindo da discussão sobre a repercussão da decisão do STF que invalidou a lei cearense sobre a vaquejada, discute-se a teoria da interpretação constitucional contemporânea. Pretende-se verificar a reflexividade do sistema jurídico na evolução da compreensão sobre o sentido do direito em uma sociedade política. Adotando o pensamento de Karl Popper como marco teórico, são apresentadas novas proposições sobre interpretação, aplicação e necessidade de postura crítica na prática jurídica. Há distinção entre interpretação e aplicação do direito como hipótese, diferenciando também a decisão jurídica de uma decisão judicial. O objetivo é refletir sobre problemas atuais da jurisdição constitucional a partir de uma revalorização da interpretação extrajudicial. Analisam-se elementos de uma possível postura hermenêutica com influências do "Racionalismo Crítico", especialmente a respeito do pensamento de Popper sobre conhecimento, parcialidade do intérprete e teoria evolucionista da interpretação. Os resultados trazem novas premissas para a discussão de uma nova compreensão da argumentação jurídica a partir de uma postura racional crítica.

PAlavras-Chave: Interpretação constitucional; Teoria da decisão; Racionalismo crítico.

\footnotetext{
${ }^{1}$ Doutor em Direito pela Freie Universität de Berlim. Professor Associado de Direito Ambiental e Constitucional da Universidade Federal de Alagoas (UFAL). E-mail: akrell@uol.com.br.

2 Mestrando em Direito na Faculdade de Direito do Recife da UFPE (FDR/UFPE).
} 


\title{
DEMOCRATIC RESPONSIBILITY AS A REQUIREMENT OF A THEORY OF INTERPRETATION: DISCUSSION ON A BRAZILIAN DECISION
}

\begin{abstract}
From a discussion about the impact of the Supreme Court decision that invalidated the legal regulation of "vaquejada" (a special type of rodeo) in the State of Ceará (Brazil), this paper discusses the theory of contemporary constitutional interpretation. The aim is to verify the reflexivity of the legal system in the evolution of understanding the meaning of law in a political society. Adopting Karl Popper's thinking as a theoretical framework, new proposals on interpretation, application and a critical stance in legal practice are presented. The necessity to distinguish between the interpretation and the application of law leaves to the differentiation between a legal and a judicial decision. The objective is to reflect on contemporary problems of the constitutional jurisdiction from a revaluation of the extrajudicial interpretation. The authors analyze elements of a possible hermeneutic posture with influences of the socalled "Critical Rationalism", especially regarding Popper's thinking about knowledge, interpretive bias and evolutionary theory of interpretation. Finally, the results of the research establish new points of view in the discussion about a adequate understanding of legal argumentation from a critical rational stance.
\end{abstract}

KEYWORDS: Constitutional interpretation; Theory of decision; Critical rationalism. 


\section{REVISTA ESTUDOS INSTITUCIONAIS}

\section{INTRODUÇÃO}

Diante da necessidade de uma análise crítica sobre a interpretação jurídica à luz de um "constitucionalismo da sociedade" ou constitucionalismo pertencente à comunidade política e não submisso exclusivamente ao poder estatal, busca-se discutir a atividade interpretativa do direito a partir de algumas questões constitucionais específicas no cenário brasileiro contemporâneo: reflexividade no processo decisório do direito, análise dos titulares da interpretação constitucional, responsabilidade democrática do intérprete e a ideia de limites da interpretação.

Para atingir os objetivos traçados na pesquisa, é realizada uma delimitação estratégica: parte-se de um problema concreto encontrado no julgamento da ADI 4983 pelo STF - que declarou inconstitucional a lei cearense que regulamentava a vaquejada (seção II). Parte-se do referido julgamento não para investigar o uso de cada argumento desenvolvido ou os métodos adotados pelos ministros, mas com a proposta de verificação de elementos que possibilitem a reflexão e, em certo sentido, a reabilitação da teoria da interpretação constitucional em sociedades que pretendem aperfeiçoar sua abertura cognitiva.

A discussão é realizada em torno de uma hipótese central: o Estado não possui o monopólio da interpretação constitucional. Assim, serão discutidas as seguintes premissas: i) nem toda forma de atribuição de significado é interpretação constitucional e esta não se confunde com a aplicação do direito (seção III); ii) os dissensos sobre o conteúdo do direito são necessários para o sistema jurídico, sendo necessária uma leitura reflexiva das decisões (seção IV); iii) a interpretação jurídica consiste em um processo contínuo e evolutivo que busca a atribuição de um significado adequado para as normas constitucionais.

Pretende-se, portanto, desenvolver um conjunto de premissas acerca da natureza da interpretação constitucional garantidora dos dissensos conteudísticos e seu diálogo com uma teoria reflexiva da decisão jurídica e com o pensamento racional-crítico de Karl Popper e Hans Albert. Não se trata de uma pesquisa que tenta tratar a interpretação constitucional com um sentido unívoco, desprezando outras teorias e olhares para a prática interpretativa do direito; é apenas o desenvolvimento de um possível olhar teórico para o problema.

Apesar de serem adotados alguns problemas no julgamento da ADI 4983 como pontos de partida, esta pesquisa não se propõe a avaliar o mérito do dispositivo decisório (saber se é constitucional uma lei que regulamenta a prática da vaquejada). Em verdade, a pretensão é expor os resultados de uma investigação no âmbito das construções 


\section{RESPONSABILIDADE DEMOCRÁTICA COMO PRESSUPOSTO DE UMA TEORIA DA INTERPRETAÇÃO}

argumentativas sobre o sentido da interpretação constitucional em contextos democráticos a partir de uma base teórica fornecida pelo Racionalismo Crítico. Trata-se, portanto, de uma observação sobre o modo como o direito é determinado e compreendido em uma dada sociedade, considerando as repercussões institucionais envolvidas no processo interpretativo do direito.

Embora muitas sejam as perspectivas e visões sobre o sentido da interpretação jurídica no controle de constitucionalidade, a pesquisa também se desenvolve em um contexto que apresenta outra funcionalidade para a interpretação jurídica: a função crítica ou científica, entendida aqui como a busca pela compreensão da norma realizada em momento anterior (ciência dogmática) e em momento posterior à aplicação do direito (interpretação crítica realizada pelos vários setores da esfera pública, além da interpretação científica novamente). Portanto, não se trata de discutir "interpretação" e "aplicação" segundo as premissas da Hermenêutica Filosófica (Gadamer). Utiliza-se, enquanto orientação teórica geral, o pensamento de Karl Popper, conforme será apresentado no próximo tópico.

Espera-se que sejam lançadas novas reflexões sobre a problemática a partir da apresentação dos resultados obtidos nesta pesquisa, colaborando para novos debates na teoria constitucional. Não se pretende, portanto, encerrar a questão, mas, pelo contrário, colaborar com uma "teoria plural da interpretação constitucional" que não significa curvar-se a posturas relativistas, céticas ou indiferentes.

\section{ANÁliSE DA PROBLEMÁticA LANÇADA NA ADI 4.983/CE}

Em 2016, o Supremo Tribunal Federal concluiu o julgamento da ADI 4.983/CE, entendendo que a legislação estadual cearense (Lei $\mathrm{n}^{\mathrm{o}}$. 15.299/2013) era inconstitucional. A referida lei cearense dava regulamentação à prática da vaquejada e trazia instrumentos de fiscalização e de responsabilidade dos promotores desse tipo de evento. Além disso, a lei cearense tratava a vaquejada como uma prática cultural e desportiva.

O relatório apresentado pelo Ministro Marco Aurélio - seguido pela maioria dos ministros (seis votaram pela inconstitucionalidade da lei e os outros cinco votaram pela constitucionalidade) - apontava argumentos contra a vaquejada em si. Isto é, não se deu a verificação da inconstitucionalidade por conta de algum dispositivo excessivo na lei 


\section{REVISTA ESTUDOS INSTITUCIONAIS}

JULHO/DEZEMBRO - ISSN 2447-5467

cearense, mas sim porque a prática da vaquejada seria algo extremamente cruel aos animais (não apenas ao boi, mas também ao cavalo).

O referido relator considerou como uma prática cruel que, à luz do ordenamento jurídico brasileiro, jamais poderia ser regulamentado. Assim, de acordo com a maioria dos ministros, seria impossível estabelecer uma dissociação entre vaquejada e crueldade contra os animais. Não sendo possível imaginar uma vaquejada sem crueldade aos animais, a vaquejada seria uma prática inconstitucional e nenhuma legislação poderia considerá-la como prática desportiva e cultural lícita. Logo, a relação causal entre a prática da vaquejada e a ocorrência de danos seria evidente.

Significativo notar que, em seu voto-relatório, o Ministro Marco Aurélio se baseou em laudos técnicos trazidos pelo Procurador-Geral da República para "demonstrar" a crueldade aos animais nas práticas da vaquejada. Nas palavras do Ministro Relator, "tem-se como indiscutível o tratamento cruel dispensado às espécies animais envolvidas".

Em posição diversa, os outros cinco ministros divergiram da tese da inconstitucionalidade. Para o Ministro Edson Fachin, que inaugurou a divergência, a vaquejada é uma prática cultural que estaria protegida pela Constituição Federal (ainda que de forma implícita). Utilizou, portanto, outra estratégia para dialogar com a realidade social: defendeu a necessidade de analisar o caso sob um olhar amplo. Implicitamente, acusou interpretações jurídicas elitistas que ignoram a realidade vivida por milhões de brasileiros e advertiu que seria necessário alargar o olhar do jurista para considerar a realidade social nas áreas rurais no país.

A presente pesquisa verificou que, além do Ministro Marco Aurélio, houve citação direta ou indireta, nos votos dos Ministros Barroso e Lewandowski (que seguiam o relatório), aos laudos técnicos fornecidos pelo Ministério Público Federal. Por outro lado, nos votos dos demais ministros (em especial, Luiz Edson Fachin, Gilmar Mendes e Teori Zavascki), o que se verificou foi uma completa ausência de argumentos sobre os laudos técnicos (ainda que para esclarecer suas divergências). Em razão disso, tais ministros, que votaram pela improcedência da ação e pela constitucionalidade da lei cearense, se utilizaram de argumentos como a observância da "realidade rural", atividade cotidiana incorporada aos hábitos populares de determinadas regiões do país, dentre outros termos que visam trazer os "viventes da norma" para o contexto de sua interpretação/concretização.

Para exemplificar tamanha divergência, pertinente é o argumento do Min. Zavascki: sem atacar o laudo técnico em si, ponderou que nem toda vaquejada é cruel. Isto é, o laudo técnico comprova existirem vaquejadas cruéis, mas isso não significa concluir que toda vaquejada é cruel. Não é 
uma qualidade inerente. Não existe causalidade comprovada. Assim, optou por seguir a linha de pensamento do Min. Fachin para tentar considerar a realidade social vivida por milhões de brasileiros.

Apesar da declaração de inconstitucionalidade da lei cearense (em razão da vaquejada ser uma prática cruel e, portanto, inconstitucional), diversas reações populares ocorreram pelo país, especialmente por associações de vaqueiros que chegaram a Brasília. Em pouco tempo, cerca de apenas um mês, o Congresso Nacional aprovou uma lei declarando a vaquejada como manifestação cultural nacional e patrimônio cultural imaterial. Alguns meses depois, também foi aprovada a emenda constitucional (EC 96/2016) proposta pelo senador baiano Otto Alencar (PSD) que exclui as manifestações culturais da possibilidade de serem consideradas cruéis as práticas desportivas que utilizam os animais.

Durante os trâmites legislativos para aprovação da emenda constitucional e início do ano de 2017, o STF preferiu não julgar outras leis estaduais que também regulamentavam a vaquejada de forma semelhante ao ocorrido no caso cearense: casos de Roraima (ADI 5703), Bahia (ADI 5710), Amapá (ADI 5711) e Paraíba (ADI 5713).

Na Reclamação 25869, julgada em dezembro de 2016, o Min. Zavascki reafirmou que aquela decisão tomada na ADI 4983 apenas produzia efeitos em relação à lei cearense. Neste caso da reclamatória, a Associação Brasileira dos Defensores de Direitos e Bem-Estar dos Animais - em conjunto com outras entidades - questionava decisão judicial monocrática de primeiro grau que autorizava a prática da vaquejada no Piauí.

Em síntese, diante da reação institucional e social em face do julgamento tomado pelo STF, houve, aparentemente, um recuo no entendimento jurídico da matéria.

Apesar de todas essas movimentações, a discussão parece ainda não ter sido encerrada. Ainda em 2017, o Procurador-Geral da República ajuizou ação (ADI 5772) pedindo a declaração de inconstitucionalidade da Emenda Constitucional 96/2016. Portanto, a questão não está encerrada e voltará a ser discutida no STF.

A ADI 4.983/CE traz algumas questões para serem refletidas: até que ponto a interpretação constitucional consegue lidar com "dados da realidade empírica" mediante uso de laudos técnicos? Cabe apenas ao STF interpretar a constitucionalidade da vaquejada? Existem limites para a interpretação constitucional? A interpretação se modifica com o tempo? Qual o tempo mínimo necessário para o STF rever suas interpretações?

Outras várias questões também surgem. Trata-se, portanto, de uma investigação muito mais ampla sobre a natureza e estrutura jurídicodogmática da interpretação constitucional que, embora necessária, não 


\section{REVISTA ESTUDOS INSTITUCIONAIS}

JULHO/DEZEMBRO - ISSN 2447-5467

caberia nem mesmo em uma tese de doutorado - e muito menos neste artigo, que investiga a questão de uma interpretação constitucional com limites, cujos parâmetros servem também como garantia do aperfeiçoamento das instituições políticas - sem negar a multiplicidade de opiniões e a divergência de ideias sobre o conteúdo do direito.

Tendo como base o "Racionalismo Crítico" (MAGEE, 1973, p. 58s.), sugerido por Popper (1989, p. 73), pretende-se partir do problema constatado para a formulação de hipóteses, tendo em vista a insuficiência teórica na explicação dessas questões. Tais premissas não possuem pretensão de certeza e são "falseáveis", abertas a uma necessária crítica e discussão. Afinal, sempre haverá possibilidade de erro. Cabe agora analisar as proposições analisadas neste artigo.

\section{PENSANDO SOBRE OS LIMITES DA INTERPRETAÇÃo CONSTITUCIONAL}

\section{Das especificidades da interpretação constitucional}

Para que seja possível pensar em limites da interpretação constitucional, primeiro é necessário um breve exame das suas especificidades em relação à interpretação jurídica em geral. É preciso esclarecer, primeiramente, se existe uma interpretação especificamente constitucional - objeto desta pesquisa. Em seguida, se discutirá sobre a relevância da distinção entre interpretação e aplicação do direito para se repensar a valorização da interpretação extrajudicial. Por fim, se apresentará um conjunto de reflexões sobre os limites da interpretação constitucional à luz de uma postura reflexiva no sistema jurídico.

Uma das formas de se compreender a interpretação jurídica é pensála como um "processo intelectivo que permite que sejam alcançados conteúdos normativos" (GARCIA, 2008, p. 59) a partir das "fontes do direito". Porém, Hesse (1998, p. 58) é categórico em afirmar que, com grande frequência, a interpretação jurídico-constitucional "se afasta muito das regras de interpretação por ela mesma reconhecidas". Em que consistiria tal especificidade?

Alguns juristas, como Lima (2001, p. 35), mencionam que basta perceber a natureza política da Constituição e o caráter principiológico de suas normas para justificar uma interpretação especial no âmbito constitucional. No mesmo sentido, Furtado $(2008$, p. 36ss.) examina que "a exegese constitucional passa, inevitavelmente, pela teoria dos princípios, tópico fruto das mais recentes evoluções do moderno constitucionalismo". Na sequência, este autor chega a afirmar que existe 
"praticamente consenso" sobre o caráter de norma jurídica dos princípios, adotando a máxima de que ferir um princípio seria muito mais grave do que infringir uma regra.

É possível, entretanto, discordar desse raciocínio que enfatiza uma suposta especificidade do juízo interpretativo no âmbito da Lei Maior. Toda e qualquer regra ou princípio jurídico pode possuir simultaneamente natureza política e jurídica. Ademais, esse suposto caráter principiológico - uma vez admitido - também poderia estar presente em outros ramos do sistema jurídico. Ignora, portanto, que há normas principiológicas que não são necessariamente constitucionais. Da mesma forma, também há normas constitucionais que não são principiológicas, uma vez que existem regras explícitas no texto constitucional - se for admitida a distinção entre regras e princípios sugerida por Alexy (2011, p. 103ss.). Por isso, não convence a alegação de uma interpretação especificamente constitucional.

Por outro lado, também existem posições doutrinárias - como a de José Afonso da Silva (2009, p. 661s.) - que descartam a natureza normativa dos princípios: estes são os fundamentos de qualquer regra jurídica e não espécies normativas. No entanto, a temática complexa dos princípios constitucionais não pode ser aprofundada neste artigo. De qualquer maneira, fica claro que não há unanimidade em relação a esta argumentação principiológica específica apenas em matéria constitucional.

Então, o que haveria de próprio na interpretação constitucional? Garcia $(2008,61$ s.) aponta que o nítido diferencial estaria na supremacia constitucional, sendo a interpretação diretamente influenciada pelo "caráter fundante da Constituição" e o valor hierarquicamente superior às demais normas. Resume-se ainda em três elementos basilares: evolutividade (contornos abertos ou flexíveis das disposições constitucionais), politicidade (organiza os órgãos soberanos e o processo de elaboração normativa) e a sensibilidade axiológica que garante o pluralismo.

Ademais, adiciona Bonavides (2013, p. 474ss.) que a superioridade e a natureza política da norma constitucional são suficientes para demonstrar uma natureza própria das interpretações constitucionais e que o jurista não poderia desmembrar a norma constitucional de seu "manancial político e ideológico". Adiante, o autor ressalta que existem limites para a interpretação da norma constitucional, pois esta não poderia ser sacrificada em razão do elemento político.

Em pesquisa realizada por Rabelo, Lima e Amorim (2014, p. 220ss.) sobre a interpretação especificamente constitucional, são tecidas diversas 


\section{REVISTA ESTUDOS INSTITUCIONAIS}

críticas ao emprego de "princípios da interpretação constitucional" quase sempre importadas da Alemanha - no direito brasileiro. Sustentam as autoras que o desenvolvimento teórico da interpretação constitucional avançou no cenário contemporâneo (pós-1945) em razão do reconhecimento da normatividade dos princípios inseridos na Lei Maior. Pela própria "natureza" dos princípios - em oposição às regras -, seria necessário um tratamento diferenciado na interpretação.

Logo, a interpretação especificamente constitucional seria voltada para as normas principiológicas (como os direitos fundamentais) enquanto que as regras deveriam ser interpretadas segundo os cânones tradicionais (RABELO; LIMA; AMORIM, 2014, p. 220ss.). Entretanto, como dito anteriormente, a teoria dos princípios enquanto espécies normativas não é consenso na doutrina constitucional brasileira.

Guerra Filho (1995, p. 255s.), por sua vez, enaltece a necessidade de uma hermenêutica especificamente constitucional que vá além dos métodos tradicionais. Argumenta que a Constituição é um processo (e não algo pronto e acabado) que é formado "basicamente por princípios". Ocorre, entretanto, que mesmo que os cânones tradicionais da interpretação sejam alvo de críticas, a prática demonstra algo diferente: juízes, advogados, administradores e tribunais continuam utilizando efetivamente os métodos literal, sistemático, histórico e teleológico (KRELL, 2014, p. 307). Não se deve ignorar tal realidade, mas também é preciso ser dito que a insuficiência do raciocínio tradicional diz respeito a toda interpretação jurídica (e não apenas à interpretação constitucional).

Neste momento, não se trata de detalhar todo o conjunto de possíveis críticas a esse tipo de caracterização das especificidades da interpretação constitucional, mas tão somente apresentar uma desconfiança teórica, em razão da aparente possibilidade de se encontrar esses mesmos elementos na interpretação em outros setores do direito.

Independentemente de ter ou não um caráter especial, a interpretação constitucional lida com questões essenciais, cujas consequências podem levar a uma "erosão da consciência constitucional", que decorre da indiferença pela Constituição e a torna instrumento para assegurar o poder ilimitado do Estado (HORTA, 1992, p. 20). Ora, se a norma constitucional é hierarquicamente superior, tem força normativa e dá validade às demais normas, servindo de parâmetro para todos os atos estatais, a Constituição não pode ser lida de qualquer forma.

Ainda que sejam possíveis interpretações diferentes em virtude da indeterminação do direito, isso não justifica cogitar a ausência de limites objetivos para a atividade do intérprete constitucional. Há, afinal, algum momento em que a atribuição de significado deixa de ser interpretação para ser outra coisa. Como pensar seus limites, então? 
Se o direito é uma "obra humana social" que possui força normativa que visa realizar valores, a interpretação do direito também não poderia ignorar tais valores (SICHES, 1977, p. 196).

Com base em Hesse (1998, p. 69s.), podemos afirmar que, se o intérprete "passa por cima da Constituição, ele não mais interpreta", ele, na verdade, altera ou rompe com a Constituição quando esta é quem deveria vincular o intérprete. Devendo a interpretação constitucional partir do primado do texto, este é o "limite insuperável" da atividade do intérprete.

Mas qual a motivação que leva Hesse a pensar no texto normativo como o principal limite ao intérprete? Seria a mesma justificação para a interpretação jurídica de contratos, legislações infraconstitucionais e outros atos normativos? Provavelmente não, pois a interpretação constitucional apresenta, geralmente, consequências muito mais gravosas do que a interpretação jurídica de outros atos. É que, de certa forma, a interpretação das normas constitucionais lida com temáticas muito sensíveis à própria institucionalização do poder político e sua limitação.

Nesse sentido, aponta Teubner (2016, p. 50s.) que o constitucionalismo liberal clássico se apresenta com dupla função: a fundação constitutiva e a limitação do poder político no Estado de Direito. Curioso notar que, do ponto de vista sociológico, a ideia de constitucionalismo - que envolve a interpretação constitucional - não se aplicaria apenas aos sistemas político e jurídico, mas a qualquer subsistema social. Assim, seria necessário pensar também nas regras constitutivas e limitativas de cada sistema social parcial.

Na mesma senda, Eco afirma que o intérprete pode especular sobre as mais diversas coisas e tentar uma grande variedade de significados e referentes, mas não teria o direito de dizer que a escrita pode significar qualquer coisa. Ele afirma que o "texto interpretado impõe restrições a seus intérpretes" e que "os limites da interpretação coincidem com os direitos do texto" (ECO, 1995, p. XXII).

Trazendo tal ideia para a interpretação constitucional, é claro que ao intérprete constitucional cabe avaliar diversos sentidos para diferentes pontos de partida, principalmente no tocante ao texto constitucional e aos textos presentes em outros julgados anteriores ou mesmo no Direito Comparado quando houver. Mas isso não significa que se possa atribuir qualquer sentido aos textos.

Mas, então, em que momento se dá a interpretação constitucional amparada em algum "ponto de partida" persuasivo? Seria na aplicação do direito? Para isso, é preciso fazer algumas considerações sobre o 


\section{REVISTA ESTUDOS INSTITUCIONAIS}

JULHO/DEZEMBRO - ISSN 2447-5467

momento de aplicação do direito para apresentar o entendimento aqui adotado, evitando confusões com outras propostas teóricas.

\section{Da possível distinção entre aplicação e interpretação do direito: por uma revalorização da interpretação extrajudicial}

Ao dissertar sobre os objetivos teóricos de Habermas, Filgueiras (2011, p. 285) afirma que o filosofo alemão tinha o objetivo de estabelecer uma teoria crítica da sociedade que pudesse integrar aspectos normativos com as realizações explicativas das ciências sociais. Em outras palavras, valorizava a ideia de "emancipação social" ao buscar uma sociedade não baseada apenas em produzir instrumentalidade nas suas interações. Tal propósito merece ser pensado com cautela.

Estaria o sistema jurídico servindo como mero instrumento estatal para persecução de determinadas vontades? Não seria demasiadamente arriscado imaginar que apenas os agentes estatais buscam a compreensão da norma jurídica e que apenas eles lhe dariam o sentido ao aplicar o direito no caso concreto?

Embora seja um termo muito genérico, "aplicação" jurídica diz respeito ao momento de "concreção", isto é, quando o direito é realizado, tornando-se inteligível ao incidir em casos concretos. Assim, a aplicação de uma regra jurídica ocorreria quando esta é "cumprida por condutas que lhe obedecem ou ao ser imposta por um órgão do poder público" (SALDANHA, 2003, p. 295). Estes dois cenários da aplicação jurídica - o cumprimento espontâneo da regra e imposição por uma autoridade competente - pressupõem algum grau de interpretação, tanto no sentido de compreensão da regra quanto em sua dimensão subjetiva influenciada pelos valores do intérprete. Logo, para haver aplicação do direito, é necessária a interpretação; o contrário, porém, não é igualmente verdadeiro.

Ainda que seja dito que o direito é uma experiência ou razão prática vivenciada e, consequentemente, não existe em um plano puramente abstrato, certo é que as pessoas em geral - e, especialmente, os profissionais e cientistas do direito - buscam compreender previamente o sentido das regras jurídicas. Claro que o direito não é uma especulação filosófica e não deve ser confundido com a ciência do direito: o direito é um fazer, é um esforço de solucionar conflitos através da razão (DELGADO, 2018, p. 30). Assim, a aplicação do direito "pretende produzir decisões corretas e justas, as quais a própria sociedade espera da ordem jurídica e das suas instituições" (KRELL, 2014, p. 298). Entretanto, a compreensão sobre as regras jurídicas não se dá apenas com os juízes e órgãos jurisdicionais. 


\section{RESPONSABILIDADE DEMOCRÁTICA COMO PRESSUPOSTO DE UMA TEORIA DA INTERPRETAÇÃO}

Essa atribuição prévia de sentido não é apenas uma análise textual do preceito escrito, mas também compreensão da realidade social e do contexto cultural já existente. Assim, a finalidade dessa interpretação prévia é a preparação da discussão em torno do sentido normativo, facilitando a convivência humana em sociedade e preparando os atuais e futuros aplicadores do direito. Logo, é possível haver interpretação jurídica sem aplicação do direito (embora possa pretender influenciar aplicações futuras), o que não significa dizer que trata-se de uma interpretação abstrata, nos termos aqui colocados.

Valendo-se da obra de Popper como marco teórico nessa discussão, faz mais sentido enxergar a interpretação jurídica como um processo evolutivo de compreensões da norma jurídica. Tal processo interpretativo não é "encerrado": o que encerra é a aplicação do direito diante de um caso concreto, em razão da necessária estabilidade social, segurança jurídica e respeito à coisa julgada na solução de conflitos). Novos argumentos e entendimentos podem continuar surgindo e nenhuma matéria jurídica encerra sua discussão de forma definitiva, principalmente no campo da ciência jurídica, entendida aqui como pensamento crítico e dialético, com rigor metodológico, que visa compreender o sentido das regras e princípios jurídicos.

Considerando que a interpretação doutrinária não necessariamente se volta para um caso particular, compete a ela não apenas buscar compreender o sentido textual, mas também todo o contexto social no qual este texto está inserido. Não se prende apenas ao "programa normativo" (dispositivo textual), mas a uma séria investigação sobre todo o "âmbito normativo" que a norma jurídica alcança, uma vez que a incidência da norma em uma realidade social que não é estática.

Por outro lado, também pode a interpretação constitucional versar sobre casos que já foram julgados (em leitura crítica) ou até mesmo especular casos fictícios para facilitar a compreensão dos que buscam entender o sentido da norma constitucional antes, durante ou depois de sua aplicação, pois interpretação e aplicação não necessariamente coincidem.

Esta postura de repensar e (re)valorizar a interpretação extrajudicial, ao distinguir interpretação da mera aplicação do direito, parece uma tese plausível e necessária para fugir dos riscos da instrumentalização nas interações sociais, tal como alertado anteriormente.

No campo da "democratização" da teoria da interpretação constitucional, foi essencial o trabalho desenvolvido por Häberle (1997, p. 13ss.) que defendeu uma "sociedade aberta dos intérpretes da constituição". Segundo ele, os viventes da norma acabam por interpretá- 


\section{REVISTA ESTUDOS INSTITUCIONAIS}

la, inexistindo monopólio da interpretação constitucional. Dessa forma, é impensável, tanto na teoria como na prática, a interpretação da Constituição sem o exercício ativo da cidadania e sem as "potências públicas" em sociedades plurais. Opinião pública, cidadãos, órgãos públicos, especialistas, dentre outros atores interessados, passam a participar das discussões constitucionais como (co-)intérpretes.

De fato, inexiste interpretação jurídica apartada da realidade. Apesar das significativas conclusões de Häberle, é preciso ressaltar que se trata de uma construção teórica diferente da lógica do Racionalismo Crítico, apesar da influência que Popper exerceu na tese de Häberle. O pensamento de Popper serviu de inspiração para outras teorias pertencentes a diferentes áreas do conhecimento. Na seara jurídica, mais alinhado ao pensamento da "sociedade aberta" é Zippelius (1997, p. 13s., 29) para quem as teorias são construções conceituais provisórias e mutáveis para a explicação do mundo real com contínua "experimentação" (trial and error). No caso do direito, todos os conceitos e teorias jurídicas são resultados provisórios do esforço de conhecimento, permanentemente exposto a uma crítica e correção.

Demonstrar os motivos que afastam Häberle da corrente críticoracionalista seria algo que fugiria dos objetivos deste trabalho. Após o devido exame das funções da interpretação constitucional, retorna-se à pergunta quanto aos limites desta, principalmente no caso da vaquejada. Neste momento, a questão dos limites interpretativos é encarada a partir de uma reflexividade em que o próprio sistema jurídico, por meio de suas instituições e interações, se modifica em um processo de aprendizagem conforme as reações e acontecimentos sociais.

\section{Teoria dos limites da interpretação a partir de uma visão reflexiva da decisão jurídica}

Para romper com a ideia de que não existe uma única leitura possível sobre determinado texto, não é preciso embarcar no "idealismo mágico" de que qualquer interpretação é válida e não existem interpretações absurdas. É nesse sentido que Eco (1995, p. 9) formula a ideia de uma "sobreinterpretação" ou "superinterpretação", afirmando que existem diversos tipos de uso dos textos que não correspondem às interpretações, mas que acabam por ultrapassar os limites desta. Assim, toda defesa pela liberdade da interpretação deveria iniciar com uma defesa do sentido literal dos textos.

Relevante ainda é pensar na colaboração de José Afonso da Silva (2009, p. 15) a respeito de uma "hermenêutica contextual". Para ele, a interpretação constitucional se submete às relações de contexto e pode ser 
vista como um diálogo com o texto criado e vigente na busca de sua "intencionalidade normativa", devendo o intérprete "desvendar o sentido mais profundo da Constituição". Os limites da interpretação constitucional se apresentariam em três momentos hermenêuticos distintos: hermenêutica das palavras (explicação das palavras, seu contexto factual e sentido histórico-cultural), hermenêutica do espírito (limites da interpretação à luz da ideia fundante da constituição) e hermenêutica do sentido ou contextual (análise dos limites interpretativos na compreensão dos contextos interno e externo do texto constitucional), pois assim o intérprete compreenderia a Constituição dentro do contexto pelo qual ela se move (SILVA, 2009, p. 16s.).

Ocorre, entretanto, que a totalidade da vida social humana gira em torno da linguagem e, havendo um interesse inato nos seres humanos por codificar e decifrar, a linguagem representa "o maior interesse e a consecução mais característica do homem" (WIENER, 1968, p. 84). No sistema jurídico, ainda de acordo com Wiener (1968, p. 104), as normas seriam formas de "controle ético aplicado à comunicação" e teriam dois problemas para serem discutidos: a questão do propósito geral (qual concepção de justiça será utilizada) e o problema da técnica (como efetivar o propósito geral).

Entretanto, não basta que a norma jurídica seja informada pelos princípios de justiça: deve ser clara e reproduzível, de modo que o indivíduo possa fixar antecipadamente seus direitos e deveres. Assim, se não houvesse nenhuma significação estabelecida nos termos empregados ou se a significação variasse de acordo com o intérprete, não haveria sentido que os indivíduos A e B celebrassem um contrato entre si que especificasse as obrigações e direitos de cada um. Pelo contrário, o normal na sociedade é que os indivíduos tentem empregar o máximo de clareza nos contratos para evitar resultados inesperados. As obrigações e direitos, portanto, devem ser inequívocas no texto jurídico, pois a "reprodutibilidade antecede a equidade" (WIENER, 1968, p. 105s.).

Em um Estado democrático de direito, decisão judicial e decisão jurídica não se confundem, pois a primeira diz respeito a um mero ato de um aplicador do direito em um caso concreto enquanto a segunda seria uma operação do sistema jurídico que resulta de uma cadeia comunicativa composta por vários elementos, decisões judiciais, manifestações sociais, atuação do legislador, interpretação dada por órgãos extrajudiciais, dentre outros (STAMFORD, 2016, p. 32). Assim, o sistema jurídico tentaria se adaptar às mudanças da sociedade e uma única decisão judicial (aplicação do direito) não representa, por si, a resposta do sistema como um todo. Neste caso, vale ressaltar o potencial 


\section{REVISTA ESTUDOS INSTITUCIONAIS}

papel desempenhado por uma "Sociologia constitucional" que, nas palavras de Lima (2008, p. 60), pode ser vista como um estudo do "rebuliço" e das "razões sociais" nas mudanças constitucionais e do impacto causado pela aplicação do direito constitucional na sociedade.

Uma visão reflexiva da decisão jurídica traz, portanto, importante aspecto para lidar com a temática dos limites da interpretação jurídica: a decisão jurídica passa a ser vista como resultado de disputas e decisões tomadas dentro do sistema jurídico pelas regras deste. Não sendo mero ato jurídico tomado em um caso concreto, as decisões judiciais - tal como o julgamento da ADI sobre a vaquejada - representam importantes elementos para a discussão no direito e para o amadurecimento de uma decisão sobre a questão envolvida. Porém, enquanto decisões judiciais dizem respeito à aplicação do direito e, portanto, podem ser definitivas para o caso concreto, a decisão jurídica jamais é definitiva, pois o sistema está sempre em movimento.

Assim, a interpretação jurídica constitucional contemporânea surge como a fase de buscas pela compreensão das normas constitucionais e dos exames de compatibilidade entre atos normativos e o parâmetro constitucional. Portanto, a interpretação jurídica está associada à ideia de interpretação realizada pelo sistema jurídico, compreendendo as interpretações particulares e individuais, mas não necessariamente o somatório destas. Ao se repensar a interpretação constitucional como busca da compreensão normativa no sistema jurídico, surge um aspecto extremamente relevante e constitutivo de uma teoria plural da interpretação: a responsabilidade democrática.

Pensar nos limites da interpretação a partir de uma visão reflexiva da decisão jurídica pode ser uma atitude de discussão sobre a própria autonomia e o autogerenciamento do sistema jurídico. Estes fatores guardam relação estreita com a ideia de democracia tomada aqui em um sentido de abertura cognitiva e inserção dos dissensos e opiniões dos indivíduos e das instituições nos órgãos públicos ou, em um sentido mais amplo, nas esferas públicas de discussão.

Pensar em responsabilidade democrática, nesse contexto, significa que os tribunais e juízes - enquanto aplicadores do direito - em algum grau também estão constrangidos pela necessidade de diálogo com as vozes dissonantes no sistema jurídico. Isso não significa, evidentemente, que os aplicadores do direito se curvam à vontade das maiorias políticas. Porém, apesar de não haver um vínculo propriamente dito, a argumentação e motivação das tomadas de posição diante do caso concreto precisam de um mínimo de persuasão para evitar a autodestruição do sistema jurídico e sua falta de legitimidade. 
A respeito desse sentimento de aceitabilidade social, que não se confunde com um vínculo aos discursos majoritários, existem diversas construções teóricas. A concepção de Souto (2016, p. 32) sustenta a ideia de que existe um sentimento geral de justiça sobre o dever ser, que deve estar em harmonia com o conhecimento científico-empírico atual (metodologicamente sofisticado).

No caso da ADI 4.983, essa necessidade de coerência com o conhecimento científico atual fica mais evidente a partir das argumentações construídas em torno de laudos técnicos ou mesmo em razão do discurso de perceber a realidade vivenciada por aqueles que seriam atingidos pela eventual declaração de inconstitucionalidade.

A ideia de responsabilidade democrática não é algo que se volta apenas aos aplicadores do direito. Para se pensar em uma teoria plural ou inclusiva da interpretação jurídica, é preciso que se tenha em mente que não apenas os agentes estatais buscam compreender o sentido da norma jurídica: considera-se a interpretação jurídica além de seu aspecto meramente instrumental.

O conhecimento científico-empírico - como a questão de saber se a prática da vaquejada realmente é prejudicial aos animais - é apenas provisório e potencialmente modificável (em razão de novos estudos, discussões e descobertas). Por isso, a interpretação do direito constitucional também é apenas provisória e pode vir a ser refutada por outro intérprete ou pelo mesmo intérprete que passou a adotar um novo entendimento.

Assim, cumpre examinar a falibilidade do conhecimento humano como elemento que justifica a adoção de maior abertura cognitiva do intérprete, entendida aqui como responsabilidade democrática. Passa-se a refletir a atividade interpretativa no contexto de uma sociedade cognitivamente aberta, compromissada com os esforços conjuntos dos intérpretes para a solução de problemas especificamente constitucionais.

\section{NOVAS PERSPECTIVAS PARA O ESTUDO DA INTERPRETAÇÃO JURÍDICA A PARTIR DO RACIONALISMO CRÍTICO}

\section{Responsabilidade democrática na prática interpretativa das sociedades abertas}

Popper (1998, p. 15), ao analisar algumas das dificuldades encontradas pela civilização contemporânea, enfatiza que ainda não se 


\section{REVISTA ESTUDOS INSTITUCIONAIS}

JULHO/DEZEMBRO - ISSN 2447-5467

conseguiu uma completa abertura das sociedades. Nas "sociedades fechadas", a compreensão do mundo é baseada em forças mágicas e argumentos de autoridade; mas é preciso caminhar para uma "sociedade aberta" que ponha em liberdade as faculdades críticas dos homens.

Nas ciências e também nas atitudes práticas dos indivíduos, Popper (1975, p. 25ss.) sustenta que o conhecimento se desenvolve pelo método crítico baseado em experiências e eliminação dos erros, com a proposta de teorias e sua submissão a testes severos. Isso não quer dizer que o método "comprove" qual teoria é a verdadeira: trata-se de método inconclusivo, mas aplicável. Enquanto não for demonstrada sua falsidade, a interpretação é considerada possivelmente verdadeira.

As perspectivas de Popper, Zippelius e Häberle apresentam peculiaridades próprias. Apesar de ser bem mais divulgada, no Brasil, a tese sobre a sociedade aberta dos intérpretes, é necessário ser dito que Häberle (1997, p. 30ss.) entende a interpretação constitucional como "processo aberto" diante da necessidade de integração da realidade no processo interpretativo. Assim, Häberle dá ênfase à "legitimação de novos intérpretes" como partes de "um pedaço da publicidade e da realidade da Constituição". A sociedade, nesses termos, somente será aberta na medida em que o círculo de intérpretes for ampliado, mas sem confundir os intérpretes em sentido amplo com os que atuam em sentido estrito.

Nota-se, claramente, que os esforços de Häberle não fazem parte do marco teórico crítico-racionalista suscitado por Popper, embora possa ter havido alguma influência. É que a abertura da "sociedade" não se dá pela mera ampliação do rol de intérpretes ou pela promoção formal de audiências e intervenções das potências públicas.

Zippelius (2012, p. 83ss.), por sua vez, entende o direito como "law in action", $^{\prime \prime}$ o direito concretizado e eficaz que se atualiza na realidade social. Mas não é apenas a realidade social que determina o direito: também atuam os princípios de justiça que sustentam a ordenação das relações sociais. Na linha de Häberle, o autor considera a legitimação do direito possível por meio da sociedade aberta: consensos com o maior número de membros da comunidade. No caso da interpretação constitucional, sua justiça não se dá pela avaliação da "verdade das coisas" ou questões abstratas, mas por "critérios e questões da práxis, ou seja, questões de actuação concreta" (ZIPPELIUS, 2012, p. 122ss.).

Na perspectiva do racionalismo crítico, a sociedade aberta pode ser associada à supressão de "dogmatizações" de qualquer espécie ao submeter as hipóteses de interpretação a constantes e rigorosos exames de revisão crítica (ALBERT, 1976, p. 181ss.). 
Uma vez que o fenômeno jurídico é multifacetado, é preciso refletir sobre a interdisciplinaridade do conhecimento jurídico. O intérprete deve buscar concretizar os valores constitucionais com abertura a "novos horizontes hermenêuticos que possibilitem a construção de uma sociedade democrática" (PERRUCCI, 2016, p. 359), favorecendo um desenvolvimento crítico do operador jurídico a partir do auxílio de outros conhecimentos sobre os fatos sociais e as necessidades da comunidade. Porém, isso não é algo simples.

Em antecipação a uma possível crítica ao pluralismo de intérpretes constitucionais, Garcia (2008, p. 66) é enfático em afirmar que a multiplicidade de intérpretes não pode ser vista como um risco de que a Constituição venha a se dissolver entre inúmeras interpretações, algo que poderia prejudicar a unidade constitucional. Ao estabelecer-se a distinção entre decisão judicial e decisão jurídica, isso fica ainda mais claro: o direito não pode se confundir com um ato decisório de aplicação jurídica.

\section{Pressupostos teóricos do Racionalismo Crítico e uma possível contribuição ao julgamento da ADI 4983}

Partindo da análise da ADI 4983 julgada pelo STF, foi possível observar uma problemática da teoria constitucional acerca da interpretação jurídica diante das repercussões sociais e institucionais. $\mathrm{O}$ momento de aplicação do direito pelos tribunais não encerra o processo interpretativo. Assim, os entendimentos jurídicos sobre o que é constitucional podem ser alterados com o passar do tempo, seja pela modificação do direito, dos fatos ou apenas da compreensão a respeito do significado da norma.

Segundo Popper (2013, p. 38), somente poderia ser reconhecido como científico aquilo que fosse passível de comprovação pela experiência. Não se trata, contudo, de tentar demonstrar a "verificabilidade" de hipóteses, mas sim sua "falseabilidade". É por isso que o enunciado "choverá ou não choverá amanhã" não pode ser científico, embora seja verificável, pois nem mesmo admite refutação em tese.

Semelhante com o que ocorre no campo científico, a interpretação jurídica é um processo evolutivo - não necessariamente progressista - por meio do qual se busca a melhor interpretação, a leitura mais adequada diante das circunstâncias culturais e sociais naquele momento histórico. Então, também as proposições interpretativas devem ser sempre falseáveis e provisórias, abertas à discussão argumentativa sobre sua coerência e adequação aos fatos. 


\section{REVISTA ESTUDOS INSTITUCIONAIS}

Ainda segundo Popper (1989, p. 142s.), o conhecimento é uma constante busca, a partir de teste e erro (trial and error), da fantasia humana (imaginação), da realização de observações contínuas e da discussão crítica. No caso do direito, a verdade existe e atua como ideia reguladora que impõe um dever de aproximação com o objeto. Como consequência desta "teoria evolucionista do conhecimento", nenhuma teoria/intepretação pode ser encarada como verdade final: a verdade não se confunde com a certeza do conhecimento que se tem sobre ela (MAGEE, 1973, p. 29ss.). Na filosofia, isso é o que passou a ser chamado de Racionalismo Crítico: a eterna demanda pela razão, com discussão crítica, sem jamais haver certeza sobre ter encontrado a verdade final sobre algo. Isso porque a possibilidade de erro sempre existirá (POPPER, 1999, p. 13).

Para Bonavides (2013, p. 502), a interpretação constitucional em países desenvolvidos possui um sentido diferente daquela a ser realizada em países em desenvolvimento, pois nestes deve o Poder Judiciário atuar de modo a tornar "exequível a possibilidade de o Estado Social compadecerse com o Estado de Direito num regime de equilíbrio, cuja firmeza relativa se mede por graus". Todavia, não parece convincente a tese de uma interpretação "mais livre" para satisfazer ideais de justiça ou visões parciais de desenvolvimento social.

Como, então, se deve entender a interpretação constitucional sem ignorar os necessários dissensos na sociedade?

$\mathrm{Na}$ linha de uma hermenêutica constitucional baseada no Racionalismo Crítico, existe uma recusa ao paradigma de um racionalismo clássico que, segundo Albert (1976, p. 47ss.), estava ligado ao "princípio da razão suficiente". Nesta visão, apenas era considerado verdadeiro aquilo que se tinha certeza de que era possível fundamentar. A interpretação relacionava-se, então, com a própria fundamentação e justificação.

Ao ser incluída a verificação crítica na teoria da interpretação, não se permite mais a dogmatização das soluções dos problemas. Os juízos são falíveis e inexistem autoridades epistemológicas que sejam imunes à crítica. Portanto, a existência de uma decisão sobre a inconstitucionalidade de lei estadual que regulamenta a prática da vaquejada não encerra a discussão sobre a licitude desta.

No caso da interpretação da realidade - algo que pode ser visto como problema central da ADI 4983 -, a contemplação passiva de uma "realidade refletida" não tem mais espaço; o que existe é uma atividade criativa falível. Não há revelação, mas uma construção que não é (nem pode ser) definitiva ou irrefutável (ALBERT, 1976, p. 38). Considerar as margens para críticas na recursividade do direito ou na interpretação 


\section{RESPONSABILIDADE DEMOCRÁTICA COMO PRESSUPOSTO DE UMA TEORIA DA INTERPRETAÇÃO}

extrajudicial é aspecto central para entender a crítica e o controle da aplicação do direito como elementos jurídicos - e não apenas políticos na teoria da interpretação constitucional.

Assim, a ideia de dissensos "conteudísticos" (divergências sobre o conteúdo jurídico) pode ser vista em torno da ideia de uma sociedade complexa que faz com que o sistema jurídico precise manter sua abertura cognitiva, mas que também precisa incluir o pensamento diferente na esfera pública. É nesse sentido que se admite a inclusão dos diferentes modos de agir e vivenciar, incluindo argumentos e opiniões minoritárias como "probabilidades de transformação futura dos conteúdos da ordem jurídico-política, desde que respeitadas as regras procedimentais" (NEVES, 2013, p. 144). No contexto de sociedades abertas, não apenas o sistema jurídico deve ser cognitivamente aberto, mas também os processos de interpretação e argumentação de cada sujeito.

Uma interpretação constitucional que possa garantir os dissensos conteudísticos deve ser um processo aberto que inclui diferentes intérpretes em uma rede mais complexa. Interpretar não se confunde com a aplicação do direito em um caso concreto. Ademais, interpretação constitucional é um processo de construção de significados no sistema jurídico que busca a formulação de uma decisão sobre a questão - e não apenas uma interpretação judicial circunstancial.

No caso da vaquejada, a existência de interpretações e tomadas de decisão no âmbito dos poderes Executivo e Legislativo, além dos movimentos sociais de pressão ao sistema jurídico, comprova a necessidade de uma releitura do fenômeno interpretativo no sistema jurídico. Nos contextos de uma interpretação jurídica extrajudicial, os diversos intérpretes espalhados nos vários segmentos da sociedade buscam a compreensão das relações jurídicas e de sua compatibilidade constitucional para diversas funções.

Não se trata de desvalorizar a interpretação "oficial", a aplicação do direito pelos tribunais competentes. No presente caso, é nítido seu efeito prático de invalidar uma escolha do poder legislativo local. O alerta é no sentido de que a interpretação constitucional não deve ser vista como um poder estatal em uma "sociedade fechada", semelhante ao papel desempenhado pelo argumento platônico a respeito dos reis filósofos. Cada ator participante de uma sociedade política - uma "sociedade aberta" (Popper) - pode vir a influenciar na atribuição de sentidos da norma constitucional. Ademais, sempre serão atribuídas versões provisórias (mas jamais aleatórias) de sentido.

A inexistência de uma atribuição definitiva às normas constitucionais não deve ser vista como algo negativo. Não se discute aqui a importância 


\section{REVISTA ESTUDOS INSTITUCIONAIS}

JULHO/DEZEMBRO - ISSN 2447-5467

da segurança jurídica e de estabilidade, uniformidade e integridade da jurisprudência; da mesma forma, não se trata de relativizar o conteúdo constitucional. Aliás, a relativização da verdade constitui grave "crime dos intelectuais", "uma traição à razão e à humanidade" (POPPER, 1989, p. 19). A verdade não se confunde com a certeza humana sobre ela. O que se discute, portanto, é a possibilidade de correção de erros que somente será ampliada com a devida autocrítica e com a abertura a outras críticas, independente da autorização estatal.

Todas as teorias - inclusive as construções de interpretações - são conjecturas que sempre apresentarão possibilidade de erro (POPPER, 1999 , p. 27s.), o que torna preciso se contentar com um saber conjectural e provisório. Popper (1989, p. 47ss.) chega a afirmar que é condenável a crença cega na autoridade do método científico ou nos seus resultados.

Por fim, é perceptível que essas premissas sobre a teoria da interpretação jurídica em sentido tão amplo poderiam ensejar críticas a respeito da imparcialidade dos intérpretes no controle de constitucionalidade. Neste caso, é preciso esclarecer que a pretensão de eliminar completamente os preconceitos e predisposições do intérprete constitui uma ilusão ainda presente no imaginário da sociedade. Não permitir que o intérprete exponha seus próprios preconceitos sobre determinado assunto jurídico ou fático em relação ao caso concreto é tentar disfarçar tais preconceitos como se fossem verdades com base na "fundamentação suficiente" para justificar aquilo que considera evidente (ALBERT, 1976, p. 59).

Como diz Albert (1976, p. 59), os preconceitos do intérprete são úteis para a evolução do conhecimento. Não se trata de buscar "fundamentos últimos", mas de análise das eventuais contradições e incongruências. Preconceitos, portanto, não devem ser eliminados, mas também não podem ser argumentados com base em dogmas ("verdades certas" que não permitem discussão crítica). $O$ intérprete deve assumir suas predisposições como hipóteses que devem ser objeto de "revisão constante".

No caso analisado, é possível visualizar diversos argumentos empregados na ADI 4983 que utilizam determinados "dados" científicos como dogmas, argumentos incontestáveis e infalíveis que tornariam "indiscutível" a conclusão obtida por eles, como ocorreu no próprio votorelatório do Min. Marco Aurélio. Trata-se do uso de recursos retóricos que buscam silenciar vozes dissonantes e não se preocupam com os argumentos trazidos pelos que possuem posições diferentes. Em grande parte, isso se deve ao fato de que boa parte dos profissionais do direito ainda permanece bastante influenciada pelo paradigma da "razão suficiente". 
Na ADI 4983, a argumentação desenvolvida pelo Relator Min. Marco Aurélio deixa "claro" que os laudos técnicos trazidos pelo PGR tornam "indiscutível" a existência de tratamento cruel contra as espécies animais envolvidas. Há, portanto, mera preocupação em fundamentar suficientemente seu voto-relatório sem preocupar-se com a possibilidade, por exemplo, de equívoco nos laudos.

Mais emblemática é a visível ausência de efetiva dialética entre os ministros favoráveis ou contrários à vaquejada acerca dos argumentos principais do lado oposto. De um lado, os que defendiam a inconstitucionalidade de qualquer regulamentação da vaquejada por se tratar de prática cruel com base nos laudos técnicos fornecidos pela PGR; do outro lado, os que votaram pela improcedência da razão, argumentando pela necessidade de observância da "realidade rural" e dos costumes e hábitos de determinadas regiões do país. Curiosamente, esses argumentos não foram rebatidos por um ou outro lado.

À luz de uma teoria jurídica comprometida com o Estado Democrático de Direito, vislumbra-se a existência de interpretações realizadas em momento anterior à aplicação do direito (por ex., em decisões judiciais) para tentar influenciar previamente nas escolhas do sistema jurídico. Ao mesmo tempo, por uma questão de responsabilidade democrática da própria teoria da interpretação, também não deve se ignorar a interpretação posterior à aplicação que geralmente possui a função crítica de revisar, refletir e reconstruir doutrinariamente a própria tomada de decisão no caso concreto para alertar a sociedade. Com isso, considerando a própria falibilidade do conhecimento humano, se busca evitar que novas interpretações equivocadas venham a ocorrer e também tentar influenciar a própria modificação do entendimento dos aplicadores do direito, com clara repercussão na construção da decisão jurídica - e não apenas da decisão judicial concreta.

\section{CONCLUSÕES}

Este artigo discutiu a ideia de uma interpretação garantidora dos dissensos conteudísticos a partir de alguns nortes teóricos, como a ideia de limites da interpretação, dos necessários dissensos de conteúdo e a abertura do sistema, além da distinção entre decisão jurídica da decisão judicial. Com isso, pretende-se contribuir para reflexões sobre um racionalismo jurídico crítico que redefine a interpretação jurídica no âmbito constitucional, superando a instrumentalização das relações sociais e a justificação inautêntica do poder. Contudo, é preciso reconhecer que tais questões ainda merecem maior aprofundamento e 


\section{REVISTA ESTUDOS INSTITUCIONAIS}

JULHO/DEZEMBRO - ISSN 2447-5467

reflexão: afinal, são apenas conclusões provisórias no âmbito de uma filosofia do Direito Constitucional comprometida com a autonomia do direito e com os valores democráticos.

Espera-se que a leitura do artigo possa servir para estimular novas reflexões sobre estes problemas, uma vez que é impossível responder, com absoluto grau de certeza, a todas as questões problemáticas lançadas nesta investigação. Há o risco do monopólio dos discursos sobre a interpretação da norma jurídica apenas no reduto estatal; por isso, assume-se uma posição em favor de um constitucionalismo democrático com constante vigilância jurídica (e não apenas política) à atuação dos juízes através da análise argumentativa das justificações sobre o sentido adotado para a norma jurídica. A prática jurídica precisa ser levada a sério diante da pretensão humana de diminuir as possibilidades de desrespeitos a direitos e garantias dos indivíduos. Compreender o lugar e a função da interpretação constitucional, considerando a responsabilidade democrática tanto dos julgadores quanto dos diversos atores que compõem a sociedade política, constitui um importante passo em direção ao aprimoramento das instituições.

A interpretação do direito deve ser vista como o processo de compreensão e atribuição de sentidos às normas jurídicas ao longo do tempo, evoluindo com base nas alterações da realidade social e do contexto histórico-cultural. Já a aplicação do direito é entendida aqui como um momento de cumprimento espontâneo do direito ou imposição de uma interpretação por autoridade competente para solucionar o caso concreto. Sendo, pois, distintas entre si, a interpretação e a aplicação do direito constitucional atuam com finalidades e problemas próprios.

No caso da decisão sobre a vaquejada, a relação entre o STF, o legislativo estadual e os movimentos sociais precisa ser analisada no procedimento decisório do sistema jurídico. A compreensão dos sentidos da interpretação constitucional é uma questão que versa sobre a própria legitimidade do direito em um contexto democrático e plural, sendo necessária uma avaliação sobre a ideia de interpretação jurídica que não fique presa a discursos relativistas ou meramente instrumentais.

Nesse sentido, a ADI 4.983/CE é apenas parte de uma discussão muito maior sobre uma decisão que está sendo tomada pelo sistema jurídico baseado em choques e diálogos de diferentes interpretações jurídicas sobre a constitucionalidade da prática esportiva e cultural da vaquejada, uma vez que o STF voltará a se pronunciar sobre a matéria para julgar a constitucionalidade da emenda constitucional que legalizou a vaquejada.

$\mathrm{Na}$ análise das argumentações desenvolvidas no referido julgamento, nem todos os elementos da problemática reside foram exaustivamente 


\section{RESPONSABILIDADE DEMOCRÁTICA COMO PRESSUPOSTO DE UMA TEORIA DA INTERPRETAÇÃO}

avaliados, mas destaca-se a postura interpretativa daqueles que buscam compreender e apontar o sentido das normas jurídicas. Tal como exposto na introdução deste artigo, não se trata de desenvolver uma leitura crítica sobre todos os argumentos desenvolvidos no julgamento escolhido, mas sim contribuir para a discussão dos sentidos e funcionalidades da interpretação constitucional a partir de elementos concretos que foram encontrados, de forma explícita ou não, nos discursos e nas posturas dos integrantes do Supremo Tribunal Federal.

Em síntese, o elemento democrático aqui exposto não se confunde com a mera ampliação e participação de diferentes atores no processo de tomada de decisões; o sistema jurídico necessita, com o objetivo de se aperfeiçoar e evoluir conforme seu processo de aprendizagem, repensar dois aspectos suscitados neste artigo: i) a argumentação jurídica despreocupada em descontruir os argumentos divergentes, apresentando sua fundamentação como a única possível, desconsiderando a possibilidade de erro e a existência de olhares dissonantes; ii) a evidente ausência de diálogo crítico entre os julgadores sobre os argumentos principais de cada lado.

Com isso, cabe ao jurista repensar seus métodos interpretativos para que sejam métodos críticos e não apenas meramente justificadores de suas posições. O método crítico, segundo o marco teórico aqui utilizado, se baseia justamente no olhar crítico às experiências das instituições e da sociedade brasileira ou de outras nações, buscando apresentar problemas nas teorias e conceitos já empregados. Trata-se, neste aspecto, de uma contínua busca de eliminação de erros, apresentando os argumentos para o afastamento de um ou outro entendimento e os motivos que levam o intérprete a preferir uma interpretação específica (e provisória) em detrimento de outra.

Do ponto de vista institucional, a revalorização da interpretação constitucional extrajudicial e a garantia de espaços públicos de discussão com inclusão de visões diferentes podem colaborar para que a melhor interpretação seja alcançada e para que os dissensos conteudísticos da sociedade sejam fomentados.

Entretanto, tais medidas não são suficientes para a garantia de um processo interpretativo mais plural e inclusivo. Tal como exposto neste estudo, a questão passa por um novo olhar para as teorias da argumentação jurídica, especialmente no tocante à tomada de uma nova postura dos intérpretes com foco na descoberta específica de erros e falhas argumentativas, demonstrando os motivos para a não utilização dos demais entendimentos, constatando qual o melhor entendimento 


\section{REVISTA ESTUDOS INSTITUCIONAIS}

para aquele momento específico em razão de todas as circunstâncias fáticas e histórico-culturais.

Assim, é necessário que a pesquisa continue a se desenvolver, amadurecendo as ideias aqui lançadas e desenvolvendo estas e novas premissas para que, talvez, possa se apresentar como um conjunto de hipóteses sólidas que, sendo falseáveis, dialogam com a experiência observável nos tribunais, instituições políticas e na sociedade civil em geral.

\section{REFERÊNCIAS}

ALBERT, Hans. Tratado da razão crítica. 2. ed. Trad. Idalina da Silva, Erika Gudde e Maria Monteiro. Rio de Janeiro: Tempo Brasileiro, 1976.

ALEXY, Robert. Teoria dos direitos fundamentais. 2. ed. Trad. Virgilio Afonso da Silva. São Paulo: Malheiros, 2011.

BONAVIDES, Paulo. Curso de Direito Constitucional. 28. ed. São Paulo: Malheiros, 2013.

DELGADO, José Luiz. Curso de Direito Natural. Curitiba: Juruá, 2018.

ECO, Umberto. Os limites da interpretação. São Paulo: Perspectiva, 1995.

FILGUEIRAS, Fernando. Entre o sujeito e a cognição: a Sociologia jurídica de Jürgen Habermas. In: FERREIRA, L. P.; GUANABARA, R.; JORGE, V. (orgs.). Curso de Sociologia jurídica. Rio de Janeiro: Elsevier, 2011, p. 285-312.

FURTADO, Emmanuel. Princípios e hermenêutica constitucional. Nomos - Revista do Programa de Pós-Graduação em Direito da UFC, vol. 28, n. 1, p. 35-50, Fortaleza, 2008. 
GARCIA, Eduardo. Conflito entre normas constitucionais: esboço de uma teoria geral. Rio de Janeiro: Lumen Juris, 2008.

GUERRA FILHO, Willis Santiago. Da interpretação especificamente constitucional. Revista de Informação Legislativa, a. 32, n. 128, p. 255259, Brasília, out./dez. 1995.

HÄBERLE, Peter. Hermenêutica constitucional: a sociedade aberta dos intérpretes da constituição: contribuição para a interpretação pluralista e "procedimental" da constituição. Trad. Gilmar F. Mendes. Porto Alegre: Sergio Fabris, 1997.

HESSE, Konrad. Elementos de Direito Constitucional da República Federativa da Alemanha. Trad. Luís A. Heck. Porto Alegre: Sergio Fabris, 1998.

HORTA, Raul Machado. Permanência e mudança na Constituição. Revista de Direito Administrativo, n. 188, p. 14-35, abr./jun. 1992.

KRELL, Andreas J. Entre desdém teórico e aprovação na prática: os métodos clássicos na interpretação jurídica. Revista Direito GV, vol. 10, n. 1, p. 295-320, São Paulo, 2014.

LIMA, Francisco Gérson M. A Sociologia constitucional como instrumento investigativo de desvelo das maquiagens da jurisdição constitucional. Nomos - Revista do Programa de Pós-Graduação em Direito da UFC, vol. 28, n. 1, p. 51-68, Fortaleza, 2008.

LIMA, Francisco Meton M. O resgate dos valores na interpretação constitucional: por uma hermenêutica reabilitada do Homem como “ser-moralmente-melhor". Fortaleza: ABC, 2001. 


\section{REVISTA ESTUDOS INSTITUCIONAIS}

MAGEE, Bryan. As ideias de Popper. Trad. Leonias Hegenberg e Octanny S. da Mota. São Paulo: Cultrix, 1973.

NEVES, Marcelo. Entre Têmis e Leviatã: uma relação difícil. São Paulo: Martins Fontes, 2013.

PERRUCCI, Adamo. Atuação jurídica e mudança de paradigma. Revista Constituição e Garantia de Direitos, vol. 9, n. 2, p. 350-365, Natal, 2016.

POPPER, Karl. A lógica da pesquisa científica. Trad. Leonidas Hegenberg e Octanny S. da Mota. 2. ed. São Paulo: Cultrix, 2013.

POPPER, Karl. A sociedade aberta e seus inimigos. Tomo 1. 3. ed. Trad. Milton Amado. Belo Horizonte: Itatiaia, 1998.

POPPER, Karl. Conhecimento objetivo: uma abordagem evolucionária. Trad. Milton Amado. Belo Horizonte: Itatiaia, 1975.

POPPER, Karl. Em busca de um mundo melhor. 2. ed. Trad. Teresa Curvelo. Lisboa: Fragmentos, 1989.

POPPER, Karl. Lógica das ciências sociais. 2. ed. Trad. E. Martins, A. Acquarone Filho e V. Silva. Rio de Janeiro: Tempo Brasileiro, 1999.

RABELO, Janaina; LIMA, Romana; AMORIM, Samira. A estrutura normativa da Constituição e a interpretação especificamente constitucional. Nomos - Revista do Programa de Pós-Graduação em Direito da UFC, vol. 34, n. 2, p. 207-225, Fortaleza, 2014.

SALDANHA, Nelson. Ordem e hermenêutica. 2. ed. Rio de Janeiro: Renovar, 2003. 
SICHES, Luis Recaséns. Algunas notas sobre el sentimiento jurídico. In: CAVALCANTI, Teófilo (org.). Estudos em homenagem a Miguel Reale. São Paulo: Revista dos Tribunais, 1977.

SILVA, José Afonso da. Comentário contextual à Constituição. 6. ed. São Paulo: Malheiros, 2009.

SILVA, José Afonso da. Teoria do conhecimento constitucional. São Paulo: Malheiros, 2014.

SOUTO, Cláudio. Breve histórico da Sociologia jurídica na Faculdade de Direito do Recife. Revista Acadêmica, vol. 88, n. 1, p. 22-38, Recife, jan./jun. 2016.

STAMFORD, Artur. Teoria reflexiva da decisão jurídica: direito, mudança social e movimentos sociais. Revista de Direito da UnB, vol. 2, p. 27-52, Brasília, 2016.

TEUBNER, Günther. Fragmentos constitucionais: constitucionalismo social na globalização. São Paulo: Saraiva, 2016.

WIENER, Norbert. Cibernética e sociedade: o uso humano de seres humanos. Trad. J. P. Paes. 2. ed. São Paulo: Cultrix, 1968.

ZIPPELIUS, Reinhold. Teoria Geral do Estado. 3. ed. Trad. Karin P.-A. Coutinho. Lisboa: Fundação Calouste Gulbenkian, 1997.

ZIPPELIUS, Reinhold. Filosofia do Direito. Trad. A. F. de Sousa e A. Franco. São Paulo: Saraiva/IDP, 2012.

RECEBIDO EM: 31/05/2018.

ACEITO EM: 31/08/2018. 